\title{
HOLISTICALLY ASSESSING COLLABORATIVE CULTURE IN THE AEC INDUSTRY
}

\author{
SUBMITTED: March 2019 \\ REVISED: March 2019 \\ PUBLISHED: April 2020
}

GUEST EDITORS: Jan Karlshøj \& Line Leth Christiansen

DOI: $10.36680 /$ j.itcon.2020.016

Sujesh Francis Sujan, Postdoctoral Researcher, School of Engineering, University of Liverpool, Liverpool, United Kingdom; Norwegian University of Science and Technology, Trondheim, Norway; S.F.Sujan@liverpool.ac.uk

Steve Wynford Jones, Senior Lecturer in Structural Engineering School of Engineering, University of Liverpool, Liverpool, United Kingdom; Stephen.Jones@liverpool.ac.uk

Arto Kiviniemi, Professor of Digital Architecture Design School of Architecture, University of Liverpool, Liverpool, United Kingdom; A.Kiviniemi@liverpool.ac.uk

Jacqueline Mary Wheatcroft, Professor of Forensic Psychology School of Natural and Social Sciences, University of Gloucestershire, Cheltenham, United Kingdom; jmwheatcroft@glos.ac.uk

Bwalimu Mwiya, Lecturer in Construction Management School of Engineering, University of Zambia, Lusaka, Zambia; mwiyab49@gmail.com

SUMMARY: The insufficient understanding and literature on people collaborating in the ArchitecturalEngineering-Construction (AEC) industry has prompted researchers to investigate this by conducting project-toproject comparisons. A mixed method-based comparison of two construction projects' design teams was made in order to present factors to be considered in fostering a positive collaborative culture. Client knowledge and involvement, existing relationships between teams, stronger informal collaboration, a decentralised leadership style and the adequate monetary motivation to a firm were found to be most critical. The study also assessed whether the use of holistic analysis methods can quantitatively show the differences between the projects; in particular, which project had a more positive collaborative culture. The perception based method used correlated the variance of perception of the teamwork environment and systemic risk to the projects with a more positive collaborative culture; $80 \%$ of constructs (some postulated attribute of people assumed, to reflect in test performance) supported the qualitative data. Additionally, assessments of the personalities of respondents from the project with a more collaborative culture also showed higher collective agreeableness. Findings suggest that projects with more changes, more assumptions made and uncertainty in requirements affect the collaborative culture negatively.

KEYWORDS: collaboration, construction industry, social science; personality, holistic analysis; human factor

REFERENCE: Sujesh Francis Sujan, Steve Wynford Jones, Arto Kiviniemi, Jacqueline Mary Wheatcroft, Bwalimu Mwiya (2020). Holistically assessing collaborative culture in the AEC industry. Journal of Information Technology in Construction (ITcon), Special issue: 'ECPPM 2018', Vol. 25, pg. 272-286, DOI: 10.36680/j.itcon.2020.016

COPYRIGHT: (C) 2020 The author(s). This is an open access article distributed under the terms of the Creative Commons Attribution 4.0 International (https://creativecommons.org/licenses/by/4.0/), which permits unrestricted use, distribution, and reproduction in any medium, provided the original work is properly cited. 


\section{INTRODUCTION}

A collaborative environment with positive project performance is one that involves high integration and team cohesion (Baiden, Price, \& Dainty, 2006; Dietrich, Eskerod, Dalcher, \& Sandhawalia, 2010). The aim of this paper is to identify the critical factors that teams need to consider in order to foster a highly collaborative environment at the project level in the construction industry. A range of lessons can be drawn from comparing two different collaborative cultures in the same industry (Kokkonen and Alin, 2015); what affects people on a project, what keeps them from working with each other? The answers to these questions are complex in the sense that a change in one factor might require changes in other factors to be optimal.

Cicmil and Marshall (2005) argue for the need for deeper studies departing from the perspective that construction projects are social settings. Kokkonen and Alin (2015) explain the somewhat selectiveness of literature and limited application of social scientific perspectives. The paper presents a philosophically similar approach to practice theory by investigating the reality of actual work practices (Bresnen, 2009); formed the basis of an award winning paper at the European Conference on Product and Process Modelling in 2018 (S.F. Sujan et al, 2018). Harty and Leiringer (2017) explains the tendency of construction management based research to shape or mutate based on the intended audiences; the methodological approach presented in this paper combines both qualitative and quantitative elements limiting this by allowing close comparison, thereby reducing the impact of subjectivity driven by the researcher's personal view.

By utilising an approach to collaboration that is not widely studied, this paper contributes to the understanding of the complex social processes that are part of the Project Based Inter-Organisational Networks (PBIONs) such as the construction industry. Perception based methods involve developing constructs; "some postulated attribute of people, assumed to reflect in test performance" (Cronbach and Meehl, 1955, p. 283).

Taylor (2005) explains that systemic innovation in PBIONs requires all firms to cooperate and collaborate, to make changes in a collective manner. Kent and Becerik-Gerber (2010) studied the attitudes towards the use of Integrated Project Delivery (IPD - a collaborative approach of aligning incentives and goals) and concluded that there are cultural, procedural and organisational barriers to its use. Other authors such as Weippert and Kajewski (2004), Walker and Hampson (2003) and Smyth and Pryke (2009) explain the need to study people along with technology forming the basis of the method; collaboration from the view of people. However, authors feel that there is insufficient literature in understanding what affects collaboration from the social setting; for example, from 274 articles published 2012 - 2016 in the journal Automation in Construction, only 9\% were concerned with the collaboration of people (Hjelseth, 2017). Furthermore, Alperen (2016) explains the lack of literature associated with collaborative information behaviour; only 7 articles were found in the Scopus database between 2005 and 2016.

As part of this study, the aim is to view the projects studied in a holistic manner in order to understand the underlying factors that are affecting collaboration. Fulford and Standing (2014) explain the need to view projects holistically in order to improve productivity.

The novelty of this paper is related to the following four aspects in the context of a project-to-project comparison:

- Holistic Analysis: utilising three impact constructs (impact on firm's cost, client's cost and schedule) to judge the severity of systemic risks, adapting and using perception of teamwork and assessing collective personality in the context of the construction industry;

- The presentation of critical factors that affect project level collaboration in the construction industry from the perception of the centre of the environment - people;

- Justifying the need to view collaboration interdependently between people, process and tools;

- Applying a psychosocial based methodology to assess and compare collaboration of designers in two AEC projects

\section{INTERDEPENDENCE, REFLECTION AND COLLABORATION}

Interdependence is a common phenomenon in defining collaboration in other similar industries. From the context of social work, interdependence is defined as 'interactions among professionals where each is dependent on the other to accomplish his or her goals and tasks' (Bronstein, 2003, p. 299). Wittenberg-Lyles, Parker Oliver, Demiris, \& Regehr (2010) studied collaboration in hospice teams suggesting that collaboration results from the 
interdependent nature of team members. Wittenberg-Lyles, et al. (2010, p. 265) explain that within hospice teams, interdependence occurs 'as individuals deviate from discipline specific boundaries'. This viewpoint is in agreement with Bronstein (2003, p. 299) notion that functioning interdependently requires professionals to have a 'clear distinction between their own and their collaborating professional's roles'.

Bronstein (2003) also explains the importance of reflection in the process of collaboration, which would allow the team to evaluate changes to inter-professional culture. According to definitions of collaboration in literature related to the context of this study, the reflective process is important in achieving interdependence.

In literature developed in the context of the construction industry, some studies define constructs of collaboration in an independent manner. For example, Singh, Gu, \& Wang (2011) defined the three elements of collaboration used in the definition above independently showing the lack of holistic perception when studying collaboration. As suggested by literature studied from a generalised context, there is interdependence if processes are set to be more collaborative which means that the correct mix of tools need to be used to enhance interoperation; a change in process directly affects what tools are being used and therefore, affects people. Furthermore, Singh, et al. (2011, p. 136) presents findings that suggest direct interdependence of people and processes, as 'organisations will need to develop their own data management practices to suit their team structure and project requirements'.

Weippert and Kajewski (2004, p. 2) explain the need for organisations in the construction industry to consider 'people along with technology' to 'improve their competitive edge'. Further explaining how technology and people are misaligned, meaning that the complete value of technology is not being utilised by the industry. Therefore, there is need for further understanding of what affects collaboration and how. Taylor (2005) suggests that a systemic innovation comprises not only of tools but also of processes that relate to how individuals add value, philosophically aligned with the Integrated Design and Delivery Solutions (IDDS) model. The AEC industries globally are following common patterns involving challenges in securing acceptable levels of efficiency and productivity (Li and Liu, 2012; Leviäkangas, Paik and Moon, 2017).

The derived Research Questions (RQ) are:

(1) What to consider when developing a highly collaborative environment in the construction industry? (RQ1)

(2) Can the collective variance in perception of teamwork environment holistically show the difference in collaborative culture efficiencies? (RQ2)

(3) Can the collective team variance of perception of systemic risks be linked to collaborative capacity? (RQ3)

(4) What traits of personality affect collaboration, and can collective personality be related to the ability to collaborate positively? (RQ4)

\section{THEORETICAL FRAMEWORK}

The adapted IDDS model as shown in Figure 1a focuses on integrating collaborating people, integrated processes and interoperable technologies. The IDDS model was developed as Building Information Modelling was becoming more widely used in some countries worldwide, however all traits of the IDDS model still apply to the use of digital technology at any level. People from various disciplines need to work together and coordinate information (Owen et al., 2009). Hjelseth (2017) explains the gap in literature in integrated processes and collaborating people unlike the majority of literature found in interoperable technologies - showing that digital technology is still thought of as a tool and not in a holistic manner as it should be with any systemic innovation (Taylor, 2005).

Figure $1 \mathrm{~b}$ shows the theoretical framework adopted for this study. The model reiterates the need to study collaboration based on all aspects; tools, processes and people interdependently, one affects the other and can provide insight also indicated by the overlapping traits of the IDDS model. For this reason, the research was designed to study what affects collaboration from the perspective of people who utilise the process and the tools; thereby applying a psychosocial based mixed methodology.

A project's success factors in the construction industry involve a significant number of human related factors (Chan, Scott, \& Chan, 2004). The collaborative environment is one that is affected by a number of project related factors including the individuals themselves. To study project success, it is important to study what fosters the right environment for people to cooperate and collaborate in order to have a successful project. 

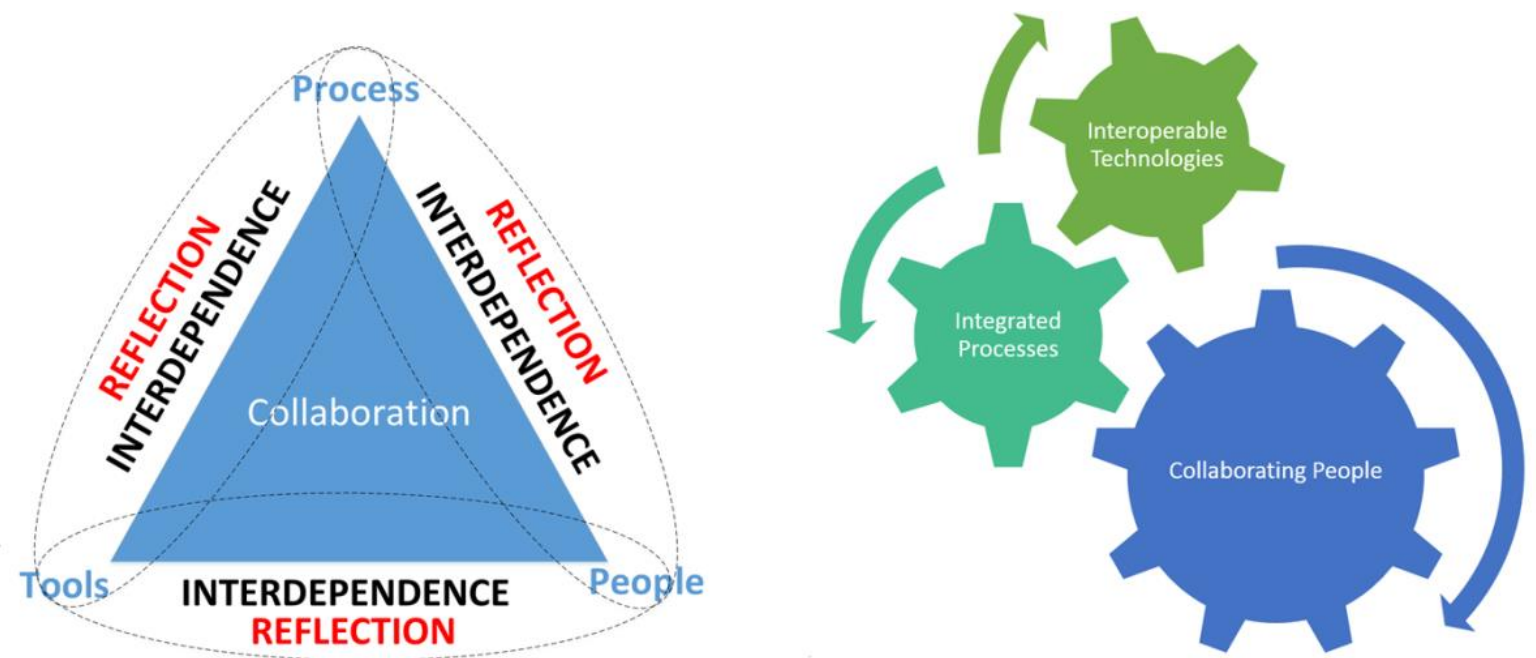

Figure la (left) : IDDS model (adapted from Owen, et al. (2009)), Figure $1 b$ (right) : Collaboration Interdependence Model

\section{THE VALUE OF THE HOLISTIC VIEW}

The study involves applying a psychosocial based methodology to investigate collaboration in project teams, a holistic perspective.

Ruppert-Winkel et al. (2015) explain the need for a connection between society and nature; Transdisciplinary Sustainability Science (TSS). TSS provides a multi-disciplinary approach to solving real world problems consisting of both scientific and non-scientific knowledge. TSS's high complexity in communication and coordination of areas studied requires significant simplification to draw findings. Furthermore, there is a need for a transparent, feasible and flexible assessment criterion of data collected depending on the goals of the project; addressed by the use of a mixed methods approach (Ruppert-Winkel, et al., 2015).

Vandenbroeck, Dechenne, Becher, Eyssen, \& Van den Heede (2014) explains that soft systems thinking focuses on developing models for intervention in real world problems utilising information gathered from the people involved in the process; a socio-technical holistic perspective. The reasons for using holistic approaches:

- A different approach to reductionist science where complex interactions are simplified to the sum of constituent parts. The method allows the use of parameters from different domains of knowledge e.g. the complex social aspects are inter-linked with the technical and business aspects in this study. As people are the centre of these links, utilising their perception based on experience can provide insight (Vandenbroeck, et al., 2014).

- Developing solutions based on feedback rather than existing theory and intuition. Researchers accept that reality is more complicated than can be perceived (Vandenbroeck, et al., 2014).

- Unlike found in natural sciences where the effect is studied based on a cause, the approach is the reverse; the study of the effect to theorise causes (Vandenbroeck, et al., 2014).

- Theories/simplification cannot help understanding problems, as there is mutual interdependence between the components in a system creating a problematic situation; relationships between components/theories are unknown (Vandenbroeck, et al., 2014).

- Methods retrieving information from actors affected by the difficulty can help us understand their social and technical nature (Vandenbroeck, et al., 2014).

- Only a partial picture of reality can be derived with reductionist/conventional science (Checkland, 2000).

- Allows dialogue between different views of the problematic situation (Checkland, 2000).

- Technical complexity is linked explicitly to social complexity (Vandenbroeck, et al., 2014).

- Academics claim that complexity science utilising a holistic view can explain 'a lot from a little' (Phelan, 2001). 


\section{PERCEPTION OF TEAMWORK ENVIRONMENT (RQ2)}

Various studies have developed methodologies to statistically visualise collaboration efficiency in similar industries using perception of team members. As people are the centre of activity in PBIONs, it is also the viewpoint in this research. PBIONs such as in the AEC industry are categorised to work similarly in industries such as healthcare, aerospace, defence and the motion picture (Taylor, 2005). From similar industries, three different studies with the same underlying philosophy were considered in the methodological development.

Sexton et al. (2006) conducted a study on the teamwork climate in labour and delivery units, which means all people involved were a part of the hospital the study was carried out in; similar to the Integrated Project Delivery way of working where there is complete vertical integration.

Similarly, from mental health networks, a study was done based on a method previously developed by Ødegård (2006) called Perception of Interprofessional Collaboration Model (PINCOM-Q). The research was conducted on 96 mental health networks in order to see the difference in quality of collaboration between mental health professionals and mental health professionals in schools.

A similar study explains the use of PINCOM-Q to study collaboration in local crime prevention; involving various professionals from social welfare, education, police, health services etc. The sample of this study is of a similar nature to that of traditionally run projects in the construction industry, as the disciplines are not governed by a group but are accountable to a client's case (Strype, Gundhus, Egge, \& Ødegård, 2014).

The three studies presented above consist of quantitative data due to the high statistical validity which can be obtained, however in the context of practitioners involved at the project level of a single construction project, statistical validity would be lacking; other means of internal validation is required, qualitative methods were adopted (Clark and Watson, 1995).

\section{SYSTEMIC RISK (RQ3)}

Systemic Risk in the context of the construction industry is a novel concept, however it has been used regularly in the financial sector. A systemic risk is one that affects all the project team firms; thereby uniting them as they all stand to lose. In this context we take advantage by presenting the practitioners with examples of situations that present systemic reactions.

Judgement of risk involves probability and severity, but when applied to systemic risks, severity is difficult to quantify (Ellinas, Allan, \& Johansson, 2016). Therefore, in order to reduce the ambiguity of severity, three separate impact constructs were introduced; impact on firm's cost, impact on client's cost and impact on the project schedule.

\section{INDIVIDUAL PERSONALITY CONSTRUCTS (RQ4)}

The researcher's experience and intuition suggest that personality plays a key part in collaboration. In the design phase of a project, personalities that adopt political or prideful stances can be a root cause for conflict between teams thereby affecting the quality of the design (Chiocchio et al. 2011). Bröchner, Josephson and Kadefors (2002), have indicated personality at a group level is important to consider with respect to factors such as leadership, participation, customer satisfaction and continuous improvement. Generally, the personality is viewed as personal characteristics that do not change in the short term (Lucas and Donnellan, 2011). Personality formed a classification part of the Hannigan (1990) study of intercultural effectiveness. A patient, courteous, flexible attitude allowing a willingness to immerse oneself in the new environment is required (Hannigan, 1990). However, individual personality traits has hardly been studied in the context of collaboration in the AEC industry.

Rothmann and Coetzer (2003) investigated the relationship between personal characteristics and job performance; positive emotional stability, openness to experience and agreeableness were found to positively affect participants' management performance. Therefore, it seems that the five-factor model of personality is useful to consider. The construct tool has been developed over the last five decades and can be assessed by using the NEO-PIR; the tool is an established personality inventory which examines an individual's Big Five personality traits (i.e., openness to experience, conscientiousness, extraversion, agreeableness, and neuroticism). 
Neuroticism is a dimension that refers to the tendency to experience negative effects such as fear, sadness, embarrassment, anger, guilt and disgust more keenly. A low score in neuroticism relates to a person who is emotionally stable, meaning, for example these individuals would cope better with stress than high scorers.

Extraversion refers to traits such as sociability, assertiveness, activity and talkativeness. Extraversion is characterised by positive feelings and experience, which makes it a positive effect (Clark and Watson, 1995). A range of studies show that extraversion is a valid performance indicator in jobs characterised by social interaction. In the context of this paper, this is valid as the construction industry is ideally tending to a highly collaborative environment. For example, Johnson (1997) found a positive correlation between extraversion and job performance of police personnel. As outlined earlier, the police work in a multidisciplinary manner similar to the construction industry making extraversion a potential important construct to consider.

Openness to Experience consists of active imagination, aesthetic sensitivity, attentiveness to inner feelings, a preference to variety, intellectual curiosity and independence of judgement. Those who score highly tend to be unconventional, willing to question authority and prepared to entertain new ethical, social and political ideas. Studies show that openness to experience is related to success in consulting (Hamilton, 1988), training (Barrick and Mount, 1991; Vinchur, Schippmann, Switzer, \& Roth, 1998) and adapting to change (Raudsepp, 1990). Based on these findings and in the context of this paper, technological change in the construction industry would require and benefit from individuals with 'openness to experience', as there is arguably a need to make changes in culture and existing ways of working.

A highly agreeable person would be fundamentally altruistic, sympathetic to others and eager to help them, and in return believes that others will be equally helpful. Judge, Higgins, Thoresen, \& Barrick (1999) concluded that the cooperative nature of agreeable individuals may lead to success in occupations where teamwork is relevant, such as in construction.

Conscientiousness involves self-control, the active process of planning, organising and carrying out tasks (Barrick, Mount, \& Strauss, 1993). A person that scores highly is purposeful, strong-willed and determined, and would be ideal in an interdisciplinary environment as work needs to be planned ahead and information needs to be provided to other disciplines on time.

\section{METHODOLOGY}

\subsection{Participants}

Two construction projects in Zambia at the design phase were selected for the study. Data was only collected from practitioners involved at the inter-organisational collaboration level. For the quantitative part of the study responses were collected from 12 respondents for Project A and 10 respondents for Project B, limited by the number of practitioners involved at the project inter-organisational level. For the qualitative part of the study 7 interviews for Project A and 8 interviews for Project B were held.

\subsection{Design, Materials and Procedure}

Selection of participants was based on convenience (not randomly) as the target was to provide a comparison on the collaborative cultures of two construction projects and it required that the participants were involved in interorganisational collaboration. The process of data collection adhered to and was approved by the ethics departments of University of Liverpool and ERES Converge's (Local Zambian Agency).

Data collection involved both qualitative and quantitative methods, done by concurrent triangulation (Creswell and Creswell, 2017). The qualitative part of the study was implemented to assess any support for the quantitative part in order to ensure that the quantitative data was comprehended with respect to reality (Fellows and Liu, 2015). The comparison of two projects' collaborative cultures involves low statistical validity due to the low number of project team participants, as only a few members of each team work at the inter-organisational level. It was decided to utilise semi-structured interviews to verify and support the quantitative data collected by asking about the practitioner's personal reflections of the project's collaborative culture. Semi-structured interviews were selected because this approach allows questioning within a flexible framework, encouraging depth and the emergence of new concepts (Dearnley, 2005). The interviewer created an environment where the interviewee could explain the difficulties in collaborating and was probed to question why these difficulties were occurring. The interviewer was also able to observe the behaviour of the interviewee when asked about project specific difficulties. The qualitative 
analytical strategy employed thematic analysis, a widely used method in psychology developed by Braun and Clarke (2006), which involves the development of themes and codes. The themes are described in the discussion with evidence of how it affects collaboration between teams from the two projects studied.

The quantitative part of the study involved a survey with four sections; general information, perception of teamwork environment, perception of systemic risk and personality.

The novelty introduced by the study is in the mixed methods approach where comparison of two projects based on the perception of practitioners at the inter-organisational level was utilised. Phua (2013) calls for the application of a combination of methods, in this context the qualitative and quantitative approaches as used by widely by psychologists and social scientists; human perception helps build mental structures about a theme (collaboration) which therefore helps participants relate the present experience with past ones (Bartlett and Burt, 1933); a form of reflection that can help the researcher understand the underlying complex factors involved in collaboration between teams.

\section{ANALYSIS AND DISCUSSION}

Collaboration is critical at the project level; every project involves collaboration. However, the literature remains uncertain on how to foster a positive collaborative environment in the context described by this paper. From the qualitative and quantitative data collected, factors that affect collaboration were developed from the comparison of two projects' collaborative cultures. Existing literature highlights the importance of culture in exchanging information and reasoning for making decisions (Avruch, 1998; Kimmel, 2000). From the two projects studied, one interviewee involved in both projects confirmed that Project B had a more positive collaborative culture fostered by openness and flexibility as compared to Project A. This section of the paper presents findings that support or negate the aforementioned RQs. Unlike RQs 2, 3 and 4, RQ 1 is an open-ended question. Although many factors are presented, the authors emphasize that collaboration cannot be limited to these factors. However, the study in the Zambian context found these factors as the most critical, from the practitioners' experience and perception.

\subsection{Similarities and Contradictions Between Cases}

Table 1. Contradiction between Project $A$ and $B$

\begin{tabular}{|l|l|l|}
\hline \multicolumn{1}{|c|}{ Contradiction } & \multicolumn{1}{c|}{ Project A } & \multicolumn{1}{c|}{ Project B } \\
\hline $\begin{array}{l}\text { Stage with Major Team } \\
\text { Involvement }\end{array}$ & Initial Design Stage & Concept Stage \\
\hline Tender Method & Cost Based & $\begin{array}{l}\text { Cost, Quality and Previous } \\
\text { Projects }\end{array}$ \\
\hline Value of Project & \$72 million & \$21 million \\
\hline Client Representation & 1 Representative & $\begin{array}{l}\text { Team of 7 Discipline Specific } \\
\text { Representatives }\end{array}$ \\
\hline Client type & Primary Client & Secondary Client \\
\hline Procurement & Design and Build & Design - BID - Build \\
\hline Fund Origin & Loan financed & Donor financed \\
\hline $\begin{array}{l}\text { Allocation of Project value } \\
\text { towards design }\end{array}$ & $4 \%$ & $6 \%$ \\
\hline $\begin{array}{l}\text { Number of Teams in consortia } \\
\text { serving client }\end{array}$ & 4 teams/firms & $\begin{array}{l}\text { Teams agreed to share .dwg files } \\
\text { and geometric coordination } \\
\text { systems }\end{array}$ \\
\hline $\begin{array}{l}\text { Data Exchange/Sharing } \\
\text { None }\end{array}$ & teams/firms \\
\hline
\end{tabular}


Table 1 summarises the contrasts between the cases. The two cases studied also had a number of similarities:

1. Both projects were led by the architect and only involved design firms from the Zambian construction industry;

2. The participants were invited to tender by advertisement in the local newspaper;

3. In both projects, the level of digital technology used was of 2D CAD drawings to develop designs of mixed-use buildings;

4. Both projects had public clients who were working with the consortia for the first time;

5. The payment method was also similar as teams were paid based on a percentage of the total cost.

\subsection{Motivation and Dedication of Teams}

From Table 1, the differences in terms of monetary value, Project A had a significantly lower percentage of total value (4\% vs. $6 \%$ of the total project budget) allocated to design teams than Project B. Although Kent and BecerikGerber (2010) concluded that monetary incentives are not the most efficient at fostering collaboration, interviewees mentioned this as a constraint to efficient project delivery and collaboration as they did not feel that the teams were allocating enough resources. 'We will sort it out on site' was a common notion from teams. Therefore, showing a lack of dedication in Project A, which may be due to the low design fees as they had projects that were more profitable.

Unlike Project B, Project A conveyed a traditional blame based culture as observed by the number of instances where interviewees placed blame on other teams. On the other hand, interviewees involved in Project B did not place any blame onto the other teams.

\subsection{Existing Relationships Between Teams}

Kent and Becerik-Gerber (2010) and Chinyio and Akintoye (2008) explain the criticality of good working relationships to a collaborative environment. The relationships between the teams with respect to the collaborative culture was probed in the semi-structured interviews. Culture is a constantly developed and changing group construct which depends on the interacting individuals (Lulofs and Cahn, 2000). The 'interacting individuals' suggest that the relationships between teams is an important factor in fostering collaboration. Figure 2 shows that Project B involved teams that worked together in a collective manner on numerous occasions bringing about strong existing relationships which affected one another's organisational cultures creating a form of unity in human interaction at the project level. Teams on Project B also developed relationships during the scope of the project, where the lead architect required input and visited similar projects in nearby countries. A number of interviewees agreed that this initial investment of time made developing the collaborative culture easier.

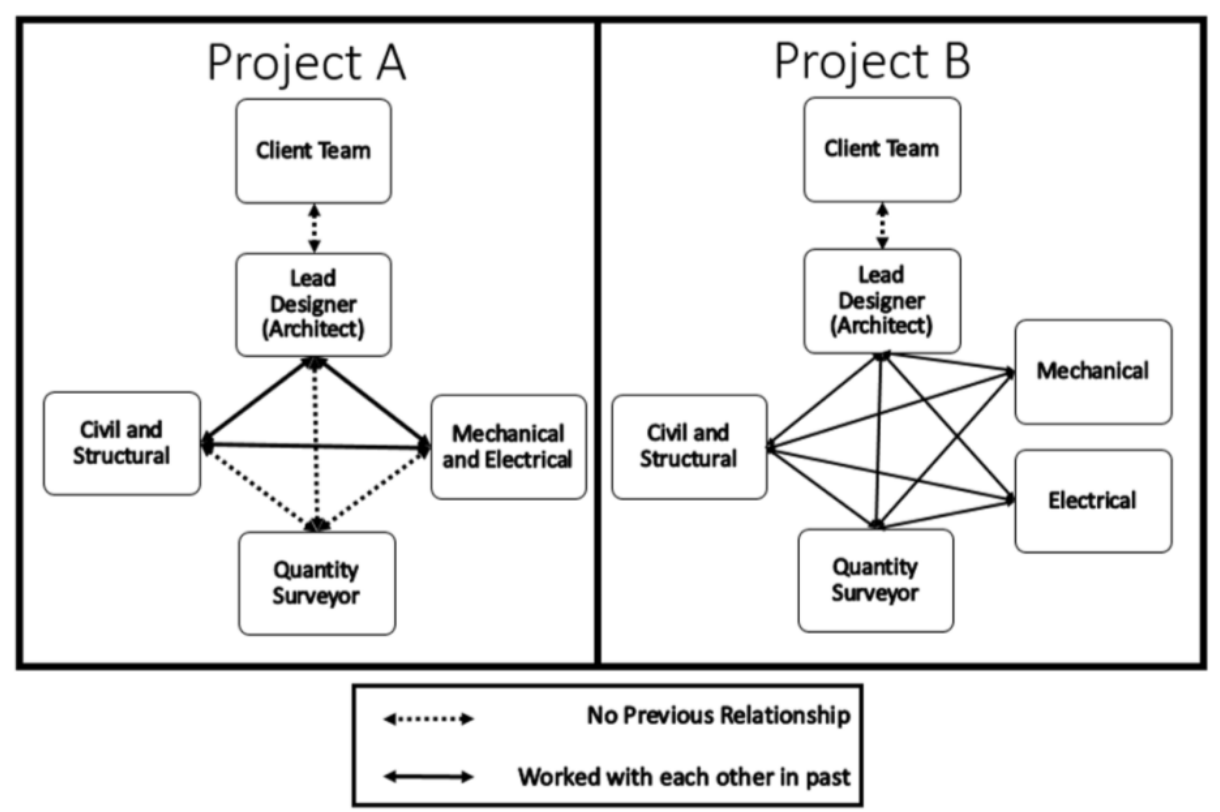

Figure 2: Structure and Relationships Between Teams 
Project A teams had some history in working together which brought about a mix of relationship strengths between the teams; suggesting a constraint in fostering project level collaboration. Furthermore, Fulford and Standing (2014) explain that efficiency is affected by 'distributed project teams' which produce non-aligned processes. The two cases studied suggest a correlation that longer existing relationships provide a more aligned work process therefore, fostering a positive collaborative culture.

\subsection{Leadership}

Good leadership is required to encourage a collaborative team environment (Kent and Becerik-Gerber, 2010). Naismith et al., (2016) explain the common belief that power can shape conflict or resolve it. Project A was run by shaping conflict as the lead designer was the centre of heated project meetings. Project B was run by trying to avoid conflict in order to resolve it by developing openness between teams.

The leadership style employed in Project A was highly diplomatic and centralised where the lead designer would be involved in all communication between teams. The lead designer of Project B approached managing teams in a decentralised manner by allowing a high level of flexibility and would only get involved when necessary, this may partially be due to the long existing relationships between the teams. This allowed for responsibility to be divided by the teams in Project B; further justified by the quantitative data. Liu, Fellows, \& Fang (2003) explain that a leadership style can increase the sense of powerlessness of project team members and negatively affect motivation; as seen in project A unlike in project B. The level of agreeance of 'I feel that the project has a clear and defined leader' (T1) showed a slightly higher level of agreement in Project A that reiterates that the lead designer in Project A was the clear leader whereas on Project B the lower agreement may be due to a culture of teams leading one another. Furthermore, agreeance with 'It is important that the lead designer arranges work in ways that helps each disciplinary group reach their goals' (T2) showed that the way the lead designer sets up communication and information exchange was more important to Project B than to Project A participants. Correlations from agreeance of 'I feel that I am not able to make significant decisions without consulting the lead designer' (T17) also show that Project B members felt that they were able to make significant decisions without consulting the lead designer; therefore given more freedom.

Bronstein (2003, p. 299) explains the need for 'the collective ownership of goals' due to the shared responsibility in making decisions in delivering a product/project for one client. Project B involved teams that lead one another unlike Project A where the lead designer was the only leader; showing higher collective ownership of goals in Project B.

\subsection{Agreeableness and Collective Understanding}

From a holistic analysis of the personalities involved in projects, it can be observed that Project B had a statistically significant higher value in collective agreeableness $(\sigma$ 2-tailed $=.018, p<.05)$ than Project $\mathrm{A}$, further validating that people in Project B are generally more sympathetic to others and eager to help. From literature, Hodges (2000) claims that a higher degree of agreeableness tends to avoid conflicts.

Bronstein (2003, p. 299) explains the need to work interdependently in collaborative environments which requires collective understanding between the teams. Both qualitative and quantitative data showed a higher level of collective understanding in Project B which may have been developed by the leadership style and long history of working. The agreeance with 'professionals from other disciplines are bad at exchanging information with each other about how they work' (T12) showed a significantly lower level of agreement in Project B ( $\sigma$ 2-tailed $=.037$, $p<=.05$ ), which further shows that the teams value understanding how others work more than in Project A. Furthermore, when respondents were asked if they felt that the lead designer should arrange work in ways to help each group, Project B showed a greater level of agreement.

The better common understanding presented by Project B was also shown by the higher agreement as they felt that they could 'rely on the other teams for help and support' (T13).

\subsection{Variance in Level of Digital Technology Between Teams}

Using the levels of digital technology defined by Eastman, Teicholz, Sacks, \& Liston (2011), Level 1 best suits the Zambian industry on average. When project level participants were asked what level of digital technology was used, a higher variance of responses came from Project A as compared to Project B. Teams involved in Project B were able to output information the way other teams required, however Project A participants exchanged 
information via the leader only. Some of the teams in Project A required paper based information unlike others that preferred files. Project A involved no formal method to coordinate information whereas Project B developed coordinate systems and grids to ensure all the geometric information could be easily layered, which best suits Level 1.

\subsection{Formal and Informal Communication}

The Project A lead designer was involved in all communication between teams by emails where he would be copied in. Whereas in Project B, teams would only involve the lead designer when needed. Furthermore, in Project B the personal relationship between the teams allowed for a significant amount of informal communication due to the collective working history of the teams.

In both projects, weekly meetings were a common form of formal communication however, interviews made it clear that the nature of meetings differed; in Project A the meetings were a lot more heated than Project B.

From the quantitative data, the higher level of agreement of 'good communication between the teams' (T11) was more efficient in Project B. Further reiterated by claims made from the statistically significant T12 are also valid in the context of communication.

Raab, Soeters, van Fenema, \& de Waard (2009) explain that organisations do not just follow the formal methods of coordinating and communicating, but they also have informal methods. Formal methods are those that are recorded, and informal are vice versa (Dainty, Moore, \& Murray, 2007). From the qualitative data, Project A had a lot more formal coordination where all information would be passed through the lead designer. Whereas, Project $\mathrm{B}$ involved more informal coordinating/communication as the teams would only involve the lead designer if necessary. The facilitation of increased informal coordinating in this context may be due to the stronger relationships between teams in Project B due to the history and early high involvement in the project. Furthermore, Chinyio and Akintoye (2008) explains that communication was seen to be an effective tool to maintain existing relationships. Like mechanisms of coordination and communication, collaboration can be categorised as informal and formal. For example, in this context, Project B was more collaborative than Project A partly because of the way informal information was flowing between teams, which was a stronger effect than the formal nature put forth by the increased fragmentation as shown in Figure 2. Furthermore, from the qualitative data, we can see that the interviewees felt more integrated with other teams in Project B. The authors believe that this was further reiterated by the holistic analysis of the quantitative data where less variance in perception of digital technology, teamwork environment and systemic risk showed a less unified perception in Project A than B.

\subsection{Client Knowledge and Involvement}

According to de Blois, Herazo-Cueto, Latunova, \& Lizarralde (2011), primary clients are those that would lease, sell, invest in buildings whereas secondary clients build to operate in the building. Project A had a primary client whereas Project B had a secondary client.

From literature it is clear that the attributes of the client affect project success (Kometa et. al 1996). The lack of client technical knowledge and involvement has a negative effect on project decision making as it makes them more cognitively bias (Sujan et al. 2019); this is because of the cultural expectations and beliefs that clients have about appointed teams or the industry, from previous encounters or common notion.

As shown in Table 1, Project A had one client representative, whereas Project B had a team consisting of 7 members. Project B had a representative for each discipline and therefore helped make discipline specific client requirements whereas Project A had one project manager who would leave it to the consortia of designers to decide. When the lead designer was asked why the client was involved at a low level, it was clear that the FIDIC contract used between client and consortia was a loan requirement and the interviewee's view was that the contract involves low client involvement to reduce the risk of corruption in a developing country. Other interviewees claimed that in Project A there was a lack of client output and when there was, the output would be delayed; forcing teams to make more assumptions driving more uncertainty into the design solution.

On the other hand, Project B had a client's team that involved an architect, civil and structural engineers, electrical engineers, mechanical engineers and a project manager who would collectively scrutinize decisions made by the design team at periodic moments of the project. The client team's aim was to ensure that the design was within the 
client requirements. They were also easily accessible to the design teams as they were delegated to their respective discipline via the lead designer.

Further strengthening the client team in Project B was the involvement of building end users who made specific changes as early as possible; reducing the uncertainty of design requirements. The client representation in Project B was clearly more knowledgeable in construction practice than in Project A which reduced the number of client driven changes which allowed for a more positive collaborative effort.

\subsection{First Involvement of Teams}

A key difference between the projects procurement was when the teams got involved. In Project A, teams were selected by the lead designer in the initial design stage, however in Project B the concept was designed carefully taking into account the views of the other design firms. Teams in Project B had the opportunity to visit similar projects together and openly voice concerns of the concepts presented by the architect with respect to their discipline related experience. Unlike Project B, interviewees from Project A commonly explained that teams felt that goals were independent to one another therefore only the work required was done unlike in Project B where it was easier to raise awareness of a problem that they see coming. From the interviews, it is clear that Project A has a higher number of changes during the design phase than Project B. Views from the interviewees suggest that if the participants of Project A had been involved earlier, the number of changes would decrease. This suggests that the discipline related experience is critical in developing a more successful concept which would therefore reduce the number of changes during the design phase, and thereby increase the efficiency of team working.

\subsection{Holistic Analysis}

Franz, Leicht, Messner, \& Molenaar (2017) concluded that more integrated and cohesive teams led to better cost, schedule and quality outcomes, therefore validating the holistic analysis. The qualitative data clearly justifies that Project B is more efficient in its delivery of output due to the more positive collaborative environment that was engendered by numeral factors, some of which have been discussed earlier. Furthermore, from the respondent/interviewee who participated in both projects it was clear that Project B was more efficient than Project A, although the culture of the teams was not of her preference. For example:

'If we gave the drawings from Project A to the contractor without being involved, it would make no sense to them, they would rather start the design again. However, in Project B, everything is well coordinated and can be constructed without significant changes or input from the design teams.' (Electrical Engineer in Project A and B)

Fulford and Standing (2014) explain the need to view organisations in a holistic manner in order to improve the productivity in the construction industry. This paper provides a quantitative approach that can be used to assess the alignment of people's way of thinking in a particular project. The qualitative data was utilised to support the holistic findings. Furthermore, such holistic methodologies have been used in a number of similar industries such as healthcare where inefficient collaboration could lead to fatality. However, a key difference is in the number of respondents, reliability of quantitative data solely depends on the statistical validity; to counteract this limitation, qualitative data was introduced.

From the teamwork part of the quantitative data, there was less variance (as illustrated by standard deviation) in $78 \%$ of the data collected from Project B despite higher fragmentation and two more respondents. Therefore, justifying the hypothesis made to devise RQ2 - the variance in perception of the teamwork environment is related to positive collaborative culture efficiency.

Similarly, from the systemic risk section of the quantitative data we can see that $80 \%$ of the impact constructs provided a higher standard deviation in Project A. This supports the hypothesis that the project that has less variance in perception of systemic risk would be more efficient at collaborating. With respect to RQ3 the results suggest a correlation between perception of systemic risk and alignment of perception and therefore indicate that the alignment in perception plays a part in how efficient a team can be in collaborating.

Project B was more fragmented (with one additional firm) and had more respondents; both of which could bring in more variance with respect to Project B. Despite the increased probability for higher variance in Project B, the variance in perception of systemic risks and teamwork environment was lower in $80 \%$ of the constructs. Therefore, holistically the differences between the projects aligned with the views from the qualitative data; Project B has a more positive collaborative culture than Project A, further justifying the results related to RQ2 and RQ3. 


\subsection{Limitations and Further Studies}

On the question of the method, inevitably, the design used here cannot reflect the full range of variables present in this context. Nevertheless, it could be argued that ecological validity was enhanced by the use of actual design teams. This means that the extent to which responses to interviews/surveys represent reality is enhanced (Cicourel, 1982) because they were directly obtained from current practitioners. The data would lack validation if either qualitative or quantitative were analysed independently; the quantitative data would lack statistical validity whereas the qualitative would lack focus. By conducting research in other countries' AEC industries, the generalisability of concepts can be strengthened. Furthermore, methodologically, the topic of collaboration can be studied in multiple ways. Unlike the project vs project perspective presented here, there needs to be other approaches to externally validate findings (Abowitz and Toole, 2009); studying collaboration using a one firm project management or an industry wide perspective.

The validity of the hypothesis requires further validation using other methodological approaches and in a crosscultural domain. Furthermore, this is the first study which tries to evaluate the severity of systemic risks using three separate impact constructs, impact on; schedule, cost to client and cost to firm. The results demonstrate that a certain amount of reliability can be seen as justified by the findings in the qualitative data. However, external validation is required to ensure applicability.

\section{CONCLUSIONS}

A mixed methods approach was applied to study collaboration by comparing two construction projects in Zambia. People and technology are said to be misaligned, where understanding the human factor is lacking. It was believed that the critical factors presented can be utilised to foster a positive collaborative culture (RQ1), by creating the foundation for people to cooperate and therefore collaborate. Findings suggest that projects with more changes, more assumptions and uncertainty in requirements affect the collaborative nature of the project as they affect participant behaviours negatively. Developing existing relationships between teams by early involvement and relationship building methods affects collaborative culture positively. Furthermore, history and experience of working with one another was found to align work methods and mentality, reducing the potential for conflict, increasing common understanding and thereby encouraging a positive collaborative culture. The role of client knowledge and involvement reduced the uncertainty driven by client requirements, which helped avoid a negative collaborative culture. From the projects studied, it was also found that a decentralised leadership style negatively affects developing a positive collaborative culture. Monetary value added to a firm was linked to motivation and allocation of resources and showed as critical in ensuring collective ownership of goals.

Holistic analysis as used in similar industries such as healthcare (RQ 2 and RQ 3) were also conducted utilising the quantitative data which showed that there was greater alignment (lower variance) in perception from the project with a positive collaborative culture suggesting that the variance in perception of the teamwork environment and systemic risk can indicate how well a team is collaborating. The holistic study of personality (RQ 4) showed that the project with a positive collaborative culture had a statistically higher level of collective agreeableness. Future research should be mindful of this variable.

In the grand scheme of understanding and assessment of project level collaboration, the study suggests that constructing metrics from similar industries does not achieve the accuracy needed with respect to the low number of project level collaboration participants. Additionally, the qualitative approach shows that there is need to understand the complexity of collaboration in an unstructured manner to study the interdependence between factors. Thereby suggesting that with the current state of knowledge an interpretive stance would be more suitable; assumptions need to be grounded in comprehensive interdependent social psychological studies. This interpretive approach is suitable until a domain specific collaboration research framework that brings together interdependent factors is developed by collaborating inter-disciplinary researchers. This should be done with social psychologists; from this study the project with more fragmentation was less collaborative than the project with more trust and positive culture, showing that the cultural aspects are indeed important, even though they are nontangible. 


\section{REFERENCES}

Abowitz, D. A., \& Toole, T. M. (2009). Mixed method research: Fundamental issues of design, validity, and reliability in construction research. Journal of Construction Engineering and Management, 136(1), pp. 108-116.

Alperen, M. A. (2016). Cognition to Collaboration: User-Centric Approach and Information Behaviour Theories/Models. [article]. Informing Science The International Journal of an Emerging Transdiscipline, Vol 20, Pp 001-020 (2016), p 001.

Avruch, K. (1998). Culture \& conflict resolution: US Institute of Peace Press.

Baiden, B. K., Price, A. D. F., \& Dainty, A. R. J. (2006). The extent of team integration within construction projects. [Article]. International Journal of Project Management, 24, pp. 13-23. doi:10.1016/j.ijproman.2005.05.001

Barrick, M. R., \& Mount, M. K. (1991). The big five personality dimensions and job performance: a meta-analysis. Personnel psychology, 44(1), pp. 1-26.

Barrick, M. R., Mount, M. K., \& Strauss, J. P. (1993). Conscientiousness and performance of sales representatives: Test of the mediating effects of goal setting. Journal of Applied Psychology, 78(5), p 715.

Bartlett, F. C., \& Burt, C. (1933). Remembering: A study in experimental and social psychology. British Journal of Educational Psychology, 3(2), pp. 187-192.

Braun, V., \& Clarke, V. (2006). Using thematic analysis in psychology. Qualitative research in psychology, 3(2), pp. 77-101.

Bresnen, M. (2009). Living the dream? Understanding partnering as emergent practice. Construction Management and Economics, 27(10), pp. 923-933.

Bröchner, J., Josephson, P.E. \& Kadefors, A., 2002. Swedish construction culture, management and collaborative quality practice. Building Research \& Information, 30(6), pp.392-400.

Bronstein, L. R. (2003). A model for interdisciplinary collaboration. Social work, 48(3), pp. 297-306.

Chan, A. P., Scott, D., \& Chan, A. P. (2004). Factors affecting the success of a construction project. Journal of Construction Engineering and Management, 130(1), pp. 153-155.

Checkland, P. (2000). The emergent properties of SSM in use: a symposium by reflective practitioners. Systemic Practice and Action Research, 13(6), pp. 799-823.

Chinyio, E. A., \& Akintoye, A. (2008). Practical approaches for engaging stakeholders: findings from the UK. Construction Management and Economics, 26(6), pp. 591-599. doi:10.1080/01446190802078310 Retrieved from https://doi.org/10.1080/01446190802078310

Chiocchio, F., Forgues, D., Paradis, D. \& Iordanova, I., 2011. Teamwork in integrated design projects: Understanding the effects of trust, conflict, and collaboration on performance. Project Management Journal, 42(6), pp.78-91.

Cicourel, A.V., 1982. Interviews, surveys, and the problem of ecological validity. The American Sociologist, pp.11-20.

Cicmil, S., \& Marshall, D. (2005). Insights into collaboration at the project level: complexity, social interaction and procurement mechanisms. Building Research \& Information, 33(6), pp. 523-535.

Clark, L. A., \& Watson, D. (1995). Constructing validity: Basic issues in objective scale development. Psychological assessment, 7(3), p 309.

Creswell, J. W., \& Creswell, J. D. (2017). Research design: Qualitative, quantitative, and mixed methods approaches: Sage publications.

Cronbach, L. J., \& Meehl, P. E. (1955). Construct validity in psychological tests. Psychological bulletin, 52(4), p 281.

Dainty, A., Moore, D., \& Murray, M. (2007). Communication in construction: Theory and practice: Routledge.

Dearnley, C. 2005. A reflection on the use of semi-structured interviews. Nurse Researcher (through 2013). 13(1), pp.19-28. 
de Blois, M., Herazo-Cueto, B., Latunova, I., \& Lizarralde, G. (2011). Relationships between construction clients and participants of the building industry: Structures and mechanisms of coordination and communication. Architectural Engineering and Design Management, 7(1), pp. 3-22.

Dietrich, P., Eskerod, P., Dalcher, D., \& Sandhawalia, B. (2010). The dynamics of collaboration in multipartner projects. Project Management Journal, 41(4), pp. 59-78.

Eastman, C., Teicholz, P., Sacks, R., \& Liston, K. (2011). BIM handbook: A guide to building information modeling for owners, managers, designers, engineers and contractors: Wiley. com.

Ellinas, C., Allan, N., \& Johansson, A. (2016). Project systemic risk: Application examples of a network model. [Article]. International Journal of Production Economics, 182, pp. 50-62. doi:10.1016/j.ijpe.2016.08.011

Fellows, R. F., \& Liu, A. M. (2015). Research methods for construction: John Wiley \& Sons.

Franz, B., Leicht, R., Messner, J., \& Molenaar, K. (2017). Impact of team integration and group cohesion on project delivery performance. [Article]. Journal of Construction Engineering and Management, 143(1)doi:10.1061/(ASCE)CO.1943-7862.0001219

Fulford, R., \& Standing, C. (2014). Construction industry productivity and the potential for collaborative practice. International Journal of Project Management, 32(2), pp. 315-326.

Hamilton, E. E. (1988). The facilitation of organizational change: An empirical study of factors predicting change agents' effectiveness. The Journal of applied behavioral science, 24(1), pp. 37-59.

Hannigan, T.P. 1990. Traits, attitudes, and skills that are related to intercultural effectiveness and their implications for cross-cultural training: A review of the literature. International Journal of Intercultural Relations. 14(1), pp.89-111.

Harty, C., \& Leiringer, R. (2017). The futures of construction management research. Construction Management and Economics, 35(7), pp. 392-403. doi:10.1080/01446193.2017.1306089 Retrieved from https://doi.org/10.1080/01446193.2017.1306089

Hjelseth, E. (2017). BIM Understanding and Activities. WIT Transactions on The Built Environment, 169, pp. 314.

Hodges, C. L. (2002). Teamwork, personality, and conflict resolution styles: Exploring predictive relationships.

Johnson, J. A. (1997). Seven social performance scales for the California Psychological Inventory. Human Performance, 10(1), pp. 1-30.

Judge, T. A., Higgins, C. A., Thoresen, C. J., \& Barrick, M. R. (1999). The big five personality traits, general mental ability, and career success across the life span. Personnel psychology, 52(3), pp. 621-652.

Kent, D. C., \& Becerik-Gerber, B. (2010). Understanding construction industry experience and attitudes toward integrated project delivery. [Article]. Journal of Construction Engineering \& Management, 136(8), pp. 815-825. doi:10.1061/(ASCE)CO.1943-7862.0000188

Kimmel, P. R. (2000). Culture and conflict. The handbook of conflict resolution: Theory and practice, pp. $453-$ 474.

Kokkonen, A., \& Alin, P. (2015). Practice-based learning in construction projects: a literature review. Construction Management and Economics, 33(7), pp. 513-530. doi:10.1080/01446193.2015.1062903 Retrieved from https://doi.org/10.1080/01446193.2015.1062903

Kometa S T, Olomolaiye P O, Harris F C (1996). A review of clientgenerated risks to project consultants. International Journal of Project Management, 14(5): 273-279

Leviäkangas, P., Paik, S. M. and Moon, S. (2017) 'Keeping up with the pace of digitization: The case of the Australian construction industry', Technology in Society. Elsevier, 50, pp. 33-43.

Li, Y. and Liu, C. (2012) 'Labour productivity measurement with variable returns to scale in Australia's construction industry', Architectural Science Review. Taylor \& Francis, 55(2), pp. 110-118.

Liu, A., Fellows, R., \& Fang, Z. (2003). The power paradigm of project leadership. Construction Management and Economics, 21(8), pp. 819-829. doi:10.1080/0144619032000056199 Retrieved from https://doi.org/10.1080/0144619032000056199

Lucas, R.E. and Donnellan, M.B. 2011. Personality development across the life span: Longitudinal analyses with a national sample from Germany. Journal of personality and social psychology. 101(4), p.847. 
Lulofs, R. S., \& Cahn, D. D. (2000). Conflict: From theory to action: Allyn \& Bacon.

Naismith, N., Sethi, R., GhaffarianHoseini, A., \& Tookey, J. Managing conflict in engineering projects: New Zealand experiences.

Ødegård, A. (2006). Exploring perceptions of interprofessional collaboration in child mental health care. International Journal of Integrated Care, 6(4)

Owen, R. L., Palmer, M. E., Dickinson, J. K., Tatum, C. B., Kazi, A. S., Amor, R., \& Prins, M. (2009). CIB white paper on IDDS integrated design \& delivery solutions.

Phelan, S. E. (2001). What is complexity science, really? Emergence, A Journal of Complexity Issues in Organizations and Management, 3(1), pp. 120-136.

Phua, F. T. T. (2013). Construction management research at the individual level of analysis: current status, gaps and future directions. Construction Management and Economics, 31(2), pp. 167-179. doi:10.1080/01446193.2012.707325 Retrieved from https://doi.org/10.1080/01446193.2012.707325

Raab, J., Soeters, J., van Fenema, P. C., \& de Waard, E. J. (2009). Structure in temporary organizations. Temporary organizations: prevalence, logic and effectiveness. Cheltenham: Edward Elgar, pp. 171-200.

Raudsepp, E. (1990). Are you flexible enough to succeed? Manage, 41(4), pp. 6-10.

Rothmann, S., \& Coetzer, E. P. (2003). The big five personality dimensions and job performance. SA Journal of Industrial Psychology, 29(1)

Ruppert-Winkel, C., Arlinghaus, R., Deppisch, S., Eisenack, K., Gottschlich, D., Hirschl, B., . . Selbmann, K. (2015). Characteristics, emerging needs, and challenges of transdisciplinary sustainability science: experiences from the German Social-Ecological Research Program. Ecology and Society, 20(3)

Sexton, J., Holzmueller, C., Pronovost, P., Thomas, E., McFerran, S., Nunes, J., . . Fox, H. (2006). Variation in caregiver perceptions of teamwork climate in labor and delivery units. Journal of perinatology, 26(8), pp. 463-470.

Singh, V., Gu, N., \& Wang, X. (2011). A theoretical framework of a BIM-based multi-disciplinary collaboration platform. Automation in Construction, 20(2), pp. 134-144.

Smyth, H., \& Pryke, S. (2009). Collaborative relationships in construction: developing frameworks and networks: John Wiley \& Sons.

Strype, J., Gundhus, H. I., Egge, M., \& Ødegård, A. (2014). Perceptions of interprofessional collaboration. Professions and Professionalism, 4(3)

S.F. Sujan, A. Kiviniemi, S.W. Jones, J.M. Wheatcroft, E. Hjelseth, B. Mwiya, O. Alhava, A. H. (2018) 'Holistic methodology to understand the complexity of collaboration in the construction process', in Jan Karlshoj, R. S. (ed.) eWork and eBusiness in Architecture, Engineering and Construction. Copenhagen: Taylor \& Francis.

Sujan, S.F., Kiviniemi, A., Jones, S.W., Wheatcroft, J.M., et al. (2019): Common biases in client involved decision-making in the AEC industry. Frontiers of Engineering Management. 6(2), pp.221-238, Available from: doi: https://doi.org/10.1007/s42524-019-0026-3.

Taylor, J. (2005). Three perspectives on innovation in interorganizational networks: Systemic innovation, boundary object change, and the alignment of innovations and networks. PhD, Stanford University, Stanford, $C A$

Vandenbroeck, P., Dechenne, R., Becher, K., Eyssen, M., \& Van den Heede, K. (2014). Recommendations for the organization of mental health services for children and adolescents in Belgium: use of the soft systems methodology. Health policy, 114(2), pp. 263-268.

Vinchur, A. J., Schippmann, J. S., Switzer, F. S., \& Roth, P. L. (1998). A meta-analytic review of predictors of job performance for salespeople. Journal of Applied Psychology, 83(4), pp. 586-597.

Walker, D. H. T., \& Hampson, K. (2003). (Non-fiction). Procurement strategies : a relationship-based approach.

Weippert, A., \& Kajewski, S. L. (2004). AEC industry culture: a need for change.

Wittenberg-Lyles, E., Parker Oliver, D., Demiris, G., \& Regehr, K. (2010). Interdisciplinary collaboration in hospice team meetings. Journal of Interprofessional Care, 24(3), pp. 264-273. 